\title{
Madres sociales de la aldea: la maestra española durante el nacional-catolicismo
}

Sonsoles San Román Gago'

\section{Resumen}

Mi objetivo es señalar cómo asumen la evolución de modelos culturales dos espacios histórico-generacionales de maestras formadas antes y después de la Guerra Civil que ejercen durante el nacional-catolicismo en escuelas públicas de aldeas rurales. Quiero situar el artículo en un marco que permita comprender formación de identidades desde la perspectiva del cambio social y la asimilación a los modelos culturales. Entiendo que para esas maestras los inicios en su profesión son claves para comprender en qué medida cambios sociales y modelos educativos moldean identidades por sesgo generacional. Me propongo captar identidades de género para indagar su función regeneracionista como madres sociales de la aldea. He seleccionado para ello dos diarios de maestras representativas en dos periodos históricos. La metodología cualitativa ha sido utilizada para comprender la construcción social de las identidades de la maestra a través del análisis del texto escrito y poder así contextualizar el significado del cambio social con el análisis de su propio discurso, el texto escrito. Mis hipótesis son: 1) el momento en que empiezan a ejercer es importante para comprender cómo asumen la evolución de los modelos culturales; 2) la forma en que han asimilado las fases históricas del nacional-catolicismo en aldeas rurales moldea sus estructuras psicológicas; 3) la adaptación a la cultura de las aldeas va produciendo identidades sociales y de género. He llegado a las siguientes conclusiones: 1) la maestra es una pieza clave para comprender la evolución de los modelos culturales; 2) conocer lo que quieren recordar o silenciar permite captar el modo en que han asumido o rechazado los modelos ideológicos del nacional-catolicismo; 3) el sentido que dan a lo vivido va señalando significantes que permiten comprender el modo en que han socializado a las siguientes generaciones.

\section{Palabras clave}

Maestras - Cambio social - Género - Identidades - Memorias - Nacional-catolicismo

I-Universidad Autónoma de Madrid, Madrid, España. Contacto: sonsosan@ucm.es 


\section{Social mothers in the villages: women schoolteachers during the National Catholicism period in Spain}

Sonsoles San Román Gago'

I-Universidad Autónoma de Madrid, Madrid, España.

Contact: sonsosan@ucm.es

\begin{abstract}
My objective is to point out how two generations of schoolteachers, those educated before and after the Civil War, understood the development of two cultural models which they implemented in public schools in rural villages in Spain during National Catholicism. Using their own words, I aim to recreate their lives and their relationship with the cultural structure. I understand that their generation and the beginning of their professional lives are key to understanding to what extent social changes and educational models shaped their identities. I intend to capture their gender identities to investigate the key aspects of their regenerative function as social mothers in small villages. There are few memoirs written by women teachers. I have selected two diaries of different generations. My hypotheses are: 1) when they begin to teach, it is important to understand how they address the evolution of cultural models; 2) the way they have understood the historic phases of National Catholicism in rural villages shapes their psychological profiles; 3) the adaptation to the culture of villages affects social and gender identities. Qualitative methodology has been used to understand the social construction of the identities of schoolteachers by means of the analysis of written texts and to contextualize the meaning of social change in their own discourse. I have reached the following conclusions: 1) teachers are key to understanding the evolution of cultural models; 2) knowing what they want to remember or silence allows capturing how they have accepted or rejected the ideological models of National Catholicism; 3) the meaning they give to the experience indicates how they socialized subsequent generations.
\end{abstract}

\section{Keywords}

Schoolteachers - Social change - Gender - Identities - Memoirs National Catholicism. 


\section{Planteamiento del problema}

Las motivaciones de las personas que ponen en movimiento los procesos de transformación no deben ser buscadas sólo en los recuerdos de acontecimientos lejanos, ajenos al presente para quien no lo ha vivido. Para entender fenómenos sociales, la biografía personal debe acompañar a la cronología general. Me planteo por ello adentrarme en los entresijos del cambio social y educativo a través de memorias autobiográficas en dos generaciones de maestras.

Alfonso Ortí y Santos Juliá Díaz (2013), muestran importantes desacuerdos a la hora de considerar los arañazos de la Guerra Civil en el tejido social de España, y en concreto en el sesgo generacional. Para el primero, la república y la guerra siguen siendo el fondo auténtico de la vida española (PINA, 2010). Para el segundo, la transición hacia la democracia fue posible por el germen de sosiego de una generación, la del 56 , en la que las distancias entre vencedores y vencidos desaparecieron para empujar a España hacia la transición, abriendo paso a una nueva visión de la Guerra Civil sin heridas de base histórica (JULIÁ DÍAZ, 2013).

Las autobiografías que voy a analizar están marcadas por la guerra. Maestras de dos generaciones, perciben el cambio social y educativo en las aldeas rurales de la España del nacional-catolicismo desde dos prismas ideológicos muy diferentes. En el caso de Dolores Medio (1993), formada en los idearios de la Segunda República, la relación entre su vida y los cambios sociales es constante. La referencia a la república y la guerra es el eje central de sus memorias. No es así en Julia Ortés (1998), formada en el ideario del nacional-catolicismo de los años 40. Sus escritos se caracterizan por una visión centrada en el esfuerzo personal, con omisión a la guerra y la república.

Centrándonos en las maestras, rastreamos la literatura y encontramos pocas biografías. La escasez de memorias parece indicar que han llegado a autopercibirse como personajes de escasa importancia, irrelevantes para relatar experiencias que no piensan que puedan interesar a nadie. Lo cierto es que, por el contrario, resultan clave para comprender los cambios sociales y educativos.

Aunque no era una práctica común investigar memorias de maestras, curiosamente el tema está de moda. La Fundación Pablo Iglesias ofreció unas jornadas organizadas en la Biblioteca Nacional: Maestras de la República. Una historia para el recuerdo, algunas de ellas posteriormente publicadas (VV.AA, 2012). Nunca antes se había organizado algo así en España para homenajear a un personaje que pasaba inadvertido. A lo que se añade que en 2014, el reportaje de Pilar Pérez Solano, Las maestras de la república, acaba de ganar un Goya ${ }^{1}$. ¿Qué está pasando en España para prestar esta atención a un personaje al que nunca se le había rendido homenaje?

Existen investigaciones que han tratado de profundizar en las biografías de las maestras para entender el cambio social y los procesos de transformación (ALDECOA, 1990). Carmen Agulló (2008) ha investigado sobre las maestras en Valencia, mujeres en la sombra ayudando en tareas propias de su género en la etapa más dura que ha vivido nuestro país, la Guerra Civil. Encargadas de saneamiento y asistencia médica, ayudando a niños abandonados, en asistencia infantil a través de instituciones internacionales, como la Cruz Roja y Solidaridad Antifascista Internacional, organizaciones oficiales para niños refugiados, como la Sección de Higiene Infantil del Ministerio de Sanidad e Instrucción Pública, el Consejo Nacional para la infancia evacuada, trabajando en talleres para confeccionar ropa, asistiendo a los combatientes en el frente, apoyando moralmente su esfuerzo para que no abandonaran la lucha, un trabajo voluntario de auxilio, presencia en los organismos que abastecían las ciudades, etc. La Agrupación de

1 - Los Premios Goya son los galardones otorgados de forma anual por la Academia de las Artes y las Ciencias. En 2013, Pilar Pérez Solano obtuvo el Goya al mejor documental. 
Mujeres Antifascistas, con una fuerte presencia de amas de casa, fue designada por el Gobierno para velar por los huérfanos y soldados. Julia Vigre, representante de mujeres antifascistas por el Partido Socialista en Madrid, trabajó en las mismas condiciones como maestra republicana y activista política en Madrid (SAN ROMÁN, 2015). Recientemente ha sido publicada una biografía de Justa Freire (DEL POZO ANDRÉS, 2013). Otras investigaciones han rastreado acerca de diarios y memorias (FLECHA GARCÍA, 2005). El interés por este tipo de trabajos no es ajeno a autoras como Pilar Ballarín, Esther Cortada y Carmen Benso (VIÑAO FRAGO, 2009).

Existe otro tipo de literatura autobiográfica en la explicación de los procesos sociales. Una información detallada sobre la presencia de la mujer en los años de la República y la Guerra Civil puede encontrarse en el libro de Julia Varela (2011).

En el caso de México, Oresta López y Luz Elena Galván (2008) han publicado acerca de memorias de maestras. En España, Antonio Viñao Frago $(2000,2002,2007)$ ha trabajado el tema y publicado varios artículos, uno de ellos con Víctor María Borroy (2006).

Hay publicaciones basadas en testimonios orales para conocer cómo viven e interpretan su profesión maestras de distintas generaciones: II República, nacional-catolicismo, transición democrática, posmodernidad y comienzos del siglo XXI (SAN ROMÁN, 2001, 2009). Hasta hay escritores que, sin ser maestras, han escrito en primera persona identificando el ensayo como autobiografía (BAQUEDANO, 1998).

\section{Tema objeto de estudio}

En esta ocasión me planteo comprender la posición que toman dos generaciones de maestras que han sido formadas en dos momentos de reformas educativas decisivas -antes y después de la Guerra Civil-, frente a los cambios educativos, políticos y sociales. Se trata de entender si el régimen franquista consiguió despertar un sentido del deber y una vocación acorde con el marco de la economía del régimen autárquico en estas madres sociales de la aldea. Resulta curioso en este sentido la contracción que presentan y que se encuentra determinada por el cruce ideológico entre su condición femenina, por la que son controladas por las autoridades locales, y la imagen profesional que proyectan en las aldeas que las alzan como el modelo de mujer a seguir, por la gozan o no de respeto en esas aldeas. De hecho, la vocación femenina que asumen las dos generaciones es clave para comprender la falta de aspiraciones en las maestras que ejercen en el nacional-catolicismo. La dictadura franquista consiguió exterminar las aspiraciones personales y profesionales de las maestras que ejercieron durante el primer (19391953) y el segundo franquismo (1953-1962).

La economía autárquica ideada por Franco ha afectado las estructuras psicológicas de estos dos modelos generacionales, reforzando identidades de género acordes con el ideario religioso del régimen. No obstante, el modelo ideológico que se esconde detrás del uso de las metodologías, memorísticas o lúdicas, es decisivo para comprender las diferencias generacionales. El referente para comprender el uso de diferentes metodologías nos lleva hacia las reformas educativas que han tenido lugar en España desde la II República, momento en que se aprueba por vez primera la coeducación, el laicismo y el uso de métodos lúdicos para potenciar la mirada crítica y avanzar hacia la modernidad.

He buscado diarios de maestras que sean prototipos de dos generaciones que ejercen durante el nacional-catolicismo y han sido formadas antes y después de la Guerra Civil. He elegido dos para relacionar identidades culturales y de género con sesgo generacional. Me interesa poner en relación el periodo en que comienzan a ejercer con la formación de sus identidades. Me planteo por ello realizar una aproximación a las autobiografías noveladas legadas por las maestras en función de sus rasgos generacionales para captar el modo en que rechazan o silencian la imposición de los 
modelos culturales de la etapa posterior a la Guerra Civil en aldeas rurales. La forma en que afrontan cambios y retos, así como el modo en que rechazan o silencian la imposición de los modelos culturales de la etapa posterior a la Guerra Civil en aldeas rurales, nos llevan a comprender el modo en que viven e interpretan su profesión y cómo asumen los cambios sociales y culturales.

\section{Metodología}

Parto de un pilar de análisis imprescindible en la perspectiva de la sociología: el sesgo generacional. El año de nacimiento marca las representaciones de lo vivido, los rasgos culturales asumidos, las expectativas y los retos en la vida de quienes comparten generaciones.

Sigo a Ortega (1951), Mannheim (1952), Tierno Galván (1961) y Alfonso Ortí (1987) al destacar la importancia del espacio histórico-generacional. El nuevo paradigma histórico-generacional depende del destino histórico del grupo. Las unidades generacionales son paradigmas de corrientes sociales que van creando visiones temporales de la historia. Por ello, las personas que viven experiencias comunes, están marcadas por ellas, y esto les predispone a una forma de pensar y proyectar el futuro. Una generación se sustituye por otra cuando los miembros de esa generación tienen ideas y conceptos que se ubican con la posibilidad de acción en un contexto social, político y educativo. Las nuevas generaciones ocupan un lugar y buscan una realización a través de tendencias dominantes en el tiempo. El momento en que comienzan a ejercer es importante para comprender la forma en que asumen la evolución de los modelos culturales y su lucha por la educación pública, el laicismo y la coeducación.

Una persona [...] convive durante treinta años productivos con los que nacieron veinte años después que él, y diez con los nacidos cuarenta años después. En ese espacio histórico coexisten tres generaciones que se definen por aquellos que conviven diez y treinta años con los otros grupos. [...]. En un periodo de cien años, [...] conviven tres grupos generacionales en un espacio de cuarenta años. A éste tiempo llamo espacio histórico generacional. Está definido [...] por la inexcusable referencia a actitudes e ideas. (TIERNO GALVÁN, 1961, p. 17-18).

Se trata de recuperar recuerdos, captar identidades culturales y modelos ideológicos. Las representaciones sociales que se obtienen por el análisis del texto escrito en sus diarios, permite captar la forma en que asimilan lo vivido y poner el cambio social en relación con sus experiencias profesionales.

Sus recuerdos de madurez ponen en relación la estructura social con el yo, ofreciendo una riqueza de contenidos de utilidad para los estudiosos de la educación y personas interesadas en el tema.

He seleccionado dos memorias escritas por maestras de dos espacios histórico-generacionales. Dolores Medio (1993) se forma en plena Restauración por el Plan de 1914 y es cursillista del Plan de $1931^{2}$. En plena Guerra Civil empieza su andadura profesional. Julia Ortés (1998), se forma por el Plan de 1940, accede en 1940 a la escuela pública para cubrir el vacío que se produce tras la depuración del magisterio en 1939.

\section{Definición de conceptos}

Entiendo por ideología la conciencia práctica que lleva a diferentes colectivos o grupos sociales a hacer presentes los intereses $\mathrm{y}$ conflictos que expresan y difunden en sus discursos (ALONSO, 1984).

Cuando las ideologías se realizan en los discursos y la palabra escrita aparece en posición de frase con un significado, es posible

\footnotetext{
2- Por R.D. de 30 de agosto de 1914 se regula este Plan, que unificaba los títulos de maestra y maestro elemental y superior en un único título de maestro de Primera Enseñanza, véase el artículo de Antonio Molero Pintado (1997).
} 
relacionar las representaciones ideológicas de las maestras con los condicionantes concretos de una situación (ORTÍ, 1986). Por ello, en el análisis ideológico del discurso hay que tener en cuenta el proceso de producción social de significados, valoraciones y sentidos, interpretado después en correspondencia con los conflictos reales de la situación histórica que lo engendra.

Desde esta perspectiva, la identidad de las maestras aparece como autoconciencia personal, profesional o colectiva, y emerge de los intercambios significativos que la persona realiza con su medio (MEAD, 1913). Los efectos de sus acciones individuales o colectivas en el mundo actúan como un espejo que devuelve al agente su rastro, su imagen como entidad efectiva. Los mejores espejos de nuestro ser en el mundo son nuestros semejantes representando los planos emotivos, motivacionales e instrumentales de nuestra vida. Más aún los otros orientacionales (KUHN, 1964): personas especiales que mantienen una relación biográfica con el protagonista, devolviéndole sus acciones interpretadas, proporcionándole categorías del yo, e incluso claves motivacionales para un proyecto de vida. Los hechos sociales serían relevantes, e incluso existirían subjetivamente, en la medida en que juegan un papel en la definición de una identidad personal o colectiva. Por eso los procesos de identidad, junto con las ideologías, tienen un papel estructurador de la realidad que los convierte en los ejes en torno a los cuales se organiza el estudio de las memorias que vamos a analizar.

Desde el punto de vista sociológico manejaré el término cultura como disponibilidad de valores, significaciones y prácticas adquiribles para comprender los primeros conceptos básicos de la historia y como la forma de crear y recrear conceptos. Sigo así la definición del concepto de cultura que maneja Norbert Elias (1979) para comprender el problema de la conexión entre las estructuras psicológicas individuales y las estructuras sociales.
De la misma manera utilizo los conceptos de cultura y vocación tal como los define Max Weber (1985). Cultura como dotación de significado y conjunto de creencias tan reales como las fuerzas materiales; vocación con un sentido de deber religioso que va a producir beneficios económicos en las aldeas rurales.

Entiendo por identidad el conjunto de intercambios significativos que realiza el sujeto con su medio. Con respecto al nivel simbólico de las identidades, éstas se encuentran relacionadas con elementos del pasado $\mathrm{y}$ predisponen expectativas de futuro.

Las identidades permiten comprender las claves motivacionales para un proyecto de vida, y en qué medida los hechos sociales serían o no relevantes. Estos procesos de identidad, junto con las ideologías, van dando forma a la realidad.

En este sentido, las memorias biográficas de estas maestras se convierten en los ejes en torno a los cuales se organiza el análisis del contenido en este artículo. A través del texto escrito analizaré el discurso de las maestras atendiendo a diversas variables de identificación. En la medida en que el sujeto es capaz de imaginar, se trata de captar tanto realidades vividas como deseos frustrados.

La metodología cualitativa me servirá para categorizar los recuerdos de lo vivido en dos espacios histórico-generacionales de maestras, detectar identidades sociales y modelos ideológicos que irán mostrando tanto la evolución de los modelos culturales como su relación con cambios históricos.

Entiendo ideal como modelo ideológico que se impone en un grupo de sujetos hasta determinar su percepción de la realidad por los elementos que selecciona en el proceso gnoseológico.

\section{Criterios generacionales para clasificar las memorias}

Propongo los siguientes criterios generacionales: 
- La generación de maestras sumidas en el ideario del nacional-catolicismo, como es el caso de Julia Ortés (1998), que se forma y comienza a ejercer durante el primer franquismo de los años 40. En sus vivencias recupera el pasado con escasas relaciones entre sus vivencias personales y los cambios sociales que atraviesa España. Se trata de una maestra de tiza imbuida en el ideario franquista, que utiliza metodologías memorísticas e ideologías acordes con las demandas de tal ideario. Omite todo lo relativo a sanciones del profesorado y represalias. Sus quejas se dirigen hacia envidias de hombres, que considera inadecuados por su naturaleza autoritaria para ejercer el magisterio. $\mathrm{Su}$ apoyo es hacia las maestras, algunas veces niñas con nueve años elegidas por ella misma como ayudantes por su intachable conducta moral. Por ello, Julia Ortés entiende que sus experiencias pueden ser de utilidad para otros y se coloca en el lado de los vencedores. Utilizaré el término vivencia como las experiencias que afectan esencialmente a la vida. Tiene por ello un significado más amplio que experiencia y próximo al significado del término en alemán como mundo de vida (lebenswelt).

- La generación de maestras formadas entre la Restauración y la II República, Dolores Medio (1993) comienza a ejercer en el periodo de la guerra y sufre la saña con que fueron tratados los profesionales de la educación que no eran adeptos al régimen de Franco. La autora, sujeto activo de la construcción social de la cultura escolar, narra experiencias que encajan con momentos clave de cambio cultural en España: represalias, persecuciones y sanciones. Recuerdos marcados por la Guerra Civil que reflejan secuencias psicológicas. Dolores Medio dedica el libro a sus "[...] compañeros de Magisterio. Soldados anónimos de la mejor guerra” (1993, p.53), y se sitúa en el bando de los vencidos y castigados. Se trata de una escritora reconocida, con una importante producción literaria.

Por lo que al estilo de escritura se refiere, se aprecian:
- Una memoria descriptiva, vivencias de una maestra, con referencia a determinados aspectos de la vida pública, personal o familiar, como es el caso de la autobiografía personal de Julia Ortés (1998). La autora, muy imbuida por los principios del nacional-catolicismo, se identifica desde sus comienzos profesionales con los modelos culturales de las aldeas (quizá los catorce años con los que se inicia en la profesión explican esta adaptación y aseguran su adhesión a los principios ideológicos del franquismo). Desde el comienzo del libro, muestra un sentido del deber muy vinculado al sentimiento religioso del ideario franquista. Entiendo por ideario el modelo ideológico que presenta el sujeto en dependencia con el momento histórico en que se forma y sus propias características biográficas.

Memorias escritas en primera o tercera persona. Estilo que en ocasiones mezcla ficción y realidad para devolver en el recuerdo de lo vivido la selección de imágenes recuperadas del pasado. Tal es el caso del Diario de una maestra escrito por Dolores Medio (1993), que se identifica con los idearios de la república. En su ficción de novela con base autobiográfica, he encontrado reacciones anímicas: impacto y rechazo al llegar a las aldeas, con cuyos habitantes no se identifica, se quiere marchar, todo lo que ve choca con sus modelos culturales, se siente vigilada y asediada. Hay un momento de metamorfosis en que esta joven maestra comienza a sentirse absolutamente necesaria, a acomodarse a la aldea, a renunciar a todo y a vivir la educación como un reto, un deber moral, una vocación, una labor social a la que va a entregar el tiempo de su vida privada. Es entonces cuando se despierta ese fuerte sentido del deber vinculado al sentimiento religioso.

\section{Análisis de casos concretos}

¿Cuáles son los modelos ideológicos en que se forma cada una de ellas y cómo viven sus inicios como profesionales? 
Dolores Medio (Oviedo, 1911-1996)

Las memorias de Dolores Medio, escritora y maestra, van mezclando biografía y ficción con un estilo interpretativo. En junio de 1930, con 18 años, obtiene el título de maestra de Primera Enseñanza por el Plan de 1914 (los estudios duraban cuatro años, con diez asignaturas por curso y sin necesidad de tener el bachillerato para acceder). Después amplía su formación como cursillista del Plan del 36. Comienza su andadura profesional en 1934, momento en que ingresa por oposición al cuerpo de magisterio. En el 36 le toca firmar la adhesión al Movimiento Nacional y en octubre de ese mismo año se incorpora a una pequeña escuela asturiana: Pereda, con 56 muchachos de todas las aldeas. En febrero del 37, momento en que se destruye Guernica y comienzan los éxitos bélicos del franquismo, se tiene que incorporar a su escuela de Nava. En 1939, denunciada por el párroco, expedientada y depurada del magisterio por hacer alarde de ultra-modernismo, no practicar la religión católica y usar métodos lúdicos, es expulsada de la escuela pública.

Vivió momentos duros que produjeran importantes tensiones entre sus emociones, tendencias intelectuales, convicciones y expectativas profesionales. $\mathrm{Su}$ trabajo como maestra de aldea rural está marcado por el compromiso político y social. En sus memorias va señalando los efectos devastadores de "aniquilación física, mental y social de todo aquel considerado enemigo, incluso, no afecto" (VIÑAO FRAG0, 2007, p. 179). Se trazan las secuelas psicológicas que produce en ella la depuración del magisterio, las vivencias de la Guerra Civil y sus devastadores efectos en la cultura y la educación.

La autora relata cómo vive su profesión en un contexto social y educativo que enmudeció a buena parte de los intelectuales, sectores críticos y demás afectados por las secuelas de la Guerra Civil: todos y todas, conscientes o no de ello, crecieron bajo las tinieblas del elemento irracional más eficaz para modular ideologías y conductas: el miedo (ELIAS, 1979).

Se aprecian en sus memorias fuertes dosis de frustración cultural y personal, algo compartido por toda una generación de profesionales de la educación que vive su profesión asediada, controlada y vigilada por curas, alcaldes y guardia civil, todos ellos agentes encargados de velar para proteger al Régimen.

Pertenece a una generación enmudecida, ágrafos muchos por los efectos del peso de ese miedo que cayó como plomo en sus mentes, limitando sus inquietudes intelectuales, lo que perjudicaría hasta la transición el proceso de modernización del país. En su caso, la escritura se convierte en una válvula de escape, una necesidad de vencer el miedo: a través de ella se expresará ese yo social enmudecido. Es, en este sentido, una más de las y los maestros depurados del magisterio que tuvieron que rodar kilómetros duros y quedaron a merced de los caprichos culturales del ideario del nacional-catolicismo.

\section{Julia Ortés (Badajoz, 1922-2000)}

Descriptivo, repleto de recuerdos de la escuela y los pueblos, en este libro ${ }^{3}$ no hay alusión al cambio histórico. Se trata de las vivencias de una maestra que nace en un pueblo de la provincia de Badajoz el 8 de febrero de 1922. Su padre es secretario del ayuntamiento y ella la última de 10 hermanos. En su infancia vive un ambiente católico, fervorosamente religioso, que marcará las identidades en su andadura profesional. La muerte de siete hermanos y de su propio padre, dos días después de comenzar la guerra, produce en ella secuelas físicas (resulta curioso que la autora no describa en ningún momento secuelas psicológicas) $\mathrm{y}$ termina perdiendo un ojo.

3- Se trata de una memoria autobiográfica escrita por Julia Ortés (1998) al finalizar su andadura profesional con el título de Vivencias de una maestra. La fuerza de la represión del régimen se muestra con claridad en una maestra que no asume como sujeto histórico. 
Nos situamos en los años del hambre, la década de los 40. Una España desnutrida de comida y cultura. En este panorama Julia asume ya desde los inicios el ideario y es adepta al régimen. No hay un antes y un después de la guerra, como en el caso de Dolores Medio. Alejada de ese nivel de profesionalidad, Julia comienza a ejercer terminada la guerra por el Plan del 40, que convertía a los bachilleres en maestras y maestros aprobando unas cuantas asignaturas, a las cuales en el caso de las maestras se sumaban Labores y Economía Doméstica; después de aprobar estas asignaturas se adjuntaban los Certificados de Buena Conducta de curas, alcaldes y guardia civil. ¿Por qué estos escasos requisitos? Simplemente las Escuelas de Magisterio permanecieron cerradas durante tres años. Los cuatro planes de estudio que se suceden en tan solo once años (1940, 1942, 1945 y 1950) muestran tanto las prisas por encontrar un mecanismo capaz de erradicar de una vez por todas los ideales sociales y reformistas de los republicanos, como el intento desmedido por reproducir a través de la escuela un modelo patriótico, religioso y nacional que sirva de bastón al nuevo gobierno franquista.

Ella es una más de esas maestras adeptas al régimen, junto con alféreces provisionales y personal de la iglesia sin preparación que se incorporan para cubrir espacios que han quedado desiertos. Al terminar la guerra se va a un pueblo pequeño entre montañas, donde la hacen presidenta de Acción Católica. Su misión consiste en mantener el fervor de un grupo de jóvenes; y entre sus tareas se encuentran: tocar las campañas de la iglesia, la limpieza de la iglesia, cuidar la imagen de la Virgen Santísima, etc.

La forma en que esta maestra asimila la evolución de los modelos culturales es bien distinta a la de Dolores Medio, que fue formada en el ideario republicano. Un fuerte sentimiento religioso lleva a Julia Ortés a identificarse con las autoridades locales y con el uso de los métodos memorísticos. Las expresiones que utiliza para narrar sus experiencias están repletas de una fervorosa religiosidad, que se hace más fuerte cuando se refiere a su persona como maestra: "hasta el cielo lloraba mi despedida" (ORTÉS, 1998, p. 36). Se autopercibe como mujer tocada por la vara divina para llevar a cabo la misión de regenerar a los campesinos.

\section{Identidades metodológicas}

Dolores Medio no elige la profesión por vocación, sino por su interés en las metodologías. Metodología participativa y coeducación son los lemas del ideario republicano con los que se identifica. Comprometida con las ideas renovadoras de la enseñanza, aparecen en sus recuerdos constantes referencias a innovaciones metodológicas que entran en conflicto con las identidades de los campesinos.

Las normas utilizadas por la maestra anterior habían producido valores en el alumnado acordes con los métodos memorísticos tradicionales; todo ello en un escenario desolador (con un armario que guarda celosamente banderas de España bordadas por la propia maestra, las Labores, que hasta 1968 no desaparecen del currículo de las escuelas femeninas de magisterio, y que eran motivo de orgullo y signo de distinción de clase social; mapas, etc.), y que no está pensado para producir los valores que ella quiere inculcar: tolerancia, respeto e igualdad. Los viejos y los nuevos métodos, reflejo de modelos políticos e ideológicos, entran en conflicto. Su entusiasmo renovador chocará con las paredes de una escuela que muestra la sórdida historia de España.

La única modificación que se hizo en la escuela cuando ella llegó, cincuenta años antes, consistió en retirar el crucifijo y las láminas de Historia Sagrada que adornaban las paredes, cuando el gobierno de la Segunda República decretó la enseñanza laica. "La vieja Obaya lo recogió todo amorosamente y después escupió sobre la bandera republicana" (MEDIO, 1993, p. 97).

Las innovaciones metodológicas de la república que ella quiere utilizar provocan rechazo: 
No se va a jugar a la escuela, sino a aprender, que no somos ricos, que hay que empezar enseguida a ganarse la vida [...]. Antes se enseñaba bien al que quería aprender...! Qué regletazos daba la vieja [...]. Pero como aprender, uno aprendía. (MEDIO, 1993, p. 149).

Los modelos metodológicos de Julia Ortés presentan importantes diferencias con respecto a la maestra formada en los ideales de la II República. Julia, que opta por la metodología lancasteriana, no sólo utiliza métodos memorísticos; también proyecta una imagen del hombre como persona incapacitada por su condición masculina para ser puesto a cargo de la escuela, optando por elegir entre sus alumnas (siguiendo criterios de moralidad, pues en caso de que no supieran leer o escribir, ya les enseñaría ella).

Los usos del tiempo público y privado se anudan. En un momento en el que no existía coeducación, la maestra relata dos turnos con orden de prioridad para los niños. Por la mañana era el turno de los niños y un hombre la acompañaba; por la tarde, el turno de las niñas, y una ayudante mujer la acompañaba; por la noche, el de adultos; e iban los dos.

\section{Identidad vocacional versus metamorfosis cultural en la madre social de la aldea}

En Dolores Medio se despierta el sentimiento de protección hacia los más necesitados: niños excluidos, cargados de apodos por no tener padre o haber sido abandonados por uno de ellos. Retos que despiertan en ella un fuerte sentimiento de protección, compromiso y vocación tardía. Priorizando los sentimientos por encima de los conocimientos, se convierte poco a poco en madre social de la aldea, persona imprescindible como mujer y profesional.

Vive un reto que genera una nueva forma de entender la educación en el mundo de los afectos. Frente a la realidad de la aldea, los conocimientos quedan postergados a un segundo plano; se produce en ella una importante metamorfosis y el abandono de otras expectativas en su vida profesional.

Ahora, al asimilar su papel en la aldea rural como madre del pueblo, se siente agente imprescindible para discentes y padres. Se va implicando como fuerza activa en el proceso de regeneración de los campesinos. Su referencia de identidad colectiva comienza a girar; ella, la maestra, percibe que es necesaria como madre del pueblo. La adaptación a los modelos culturales del nacional-catolicismo ha hecho mella en una maestra que sufre una metamorfosis, una vocación tardía sí, pero con una fuerte identidad vocacional.

Ahora, al hacerse otra vez cargo de la escuela [...] le exige una total entrega a su profesión [...] ¡Todo el pueblo escuela! Siempre responsable... A los ojos de los campesinos Irene había bajado de su pedestal de autoridad local para colocarse a su misma altura. (MEDIO, 1993, p. 264-270).

En el otro extremo, Julia Ortés, defensora a ultranza de la feminización y contraria a la coeducación, presenta una vocación temprana ligada a un sentido del deber, entrega y sacrificio religioso acorde al momento en que se forma, la etapa más dura, los años 40. El momento en que la religión se convierte en la referencia de la cultura de las y los españoles.

Describe un mundo de pobreza y solidaridad en las aldeas. Imágenes de orfanatos que recogen a niños y niñas, escenas de pobreza y desamparo de una infancia de la que, en algunos casos, no saben quiénes son los padres. Muchos de ellos muertos, otros en el exilio exterior y algunos escondidos en el exilio interior para evitar la muerte. Sumida en la ideología del régimen, y muy involucrada en el proceso de regeneración de unos campesinos - a quienes no tiene el menor propósito de desvincular del régimen -, es un orgullo para ella que dos de sus alumnas terminen siendo monjas. 
Los retos conseguidos van acentuando en ella un sentimiento de vocación, entrega y sacrificio. Los efectos de esta vocación la llenan de orgullo. Ella, que ya tiene 18 años, conseguirá lo que otras no han conseguido. Una niña apartada de los juegos y tachada por las demás como demonio y aborto del infierno detrás de la que se escondía una historia tétrica, pues su abuela la llevo para ver cómo fusilaban a su padre, y su madre desapareció -, será santificada por ella, la maestra, y hasta llegará a obtener el premio de Hija de María, otorgado por el colegio a las alumnas con buenas notas y conducta ejemplar - resulta un tema curioso la cantidad de medallas con imágenes religiosas que tuvieron que llevar colgadas las alumnas premiadas. (ORTÉS, 1998). Los efectos de esta asimilada vocación son claros: limitación de ambiciones profesionales en unas maestras que priorizan su vocación por encima de cualquier pretensión económica y llegan a aceptar trabajar al cien por cien de sus posibilidades sin pedir más salario, entre otras cosas al entender que no se trata de un trabajo que se elija para ganar dinero. Tengo que decir que resulta curioso el tema del uso del dinero en las distintas generaciones de maestras que he investigado: cuanto más vocacionales y religiosas, menos dicen interesarse por los ingresos y más por las recompensas y retos profesionales cumplidos.

En el imaginario de Julia, los maestros aparecen como personas envidiosas, sin formación, astutos, siempre vigilantes, controlando, cuestionando su trabajo. Destinada a un pueblo de la zona montañosa de Badajoz, relata situaciones que recuerdan la España de mediados del siglo XIX, cuando los hombres se hacían cargo de la educación, compaginando este trabajo con otros como secretario del ayuntamiento, tendero, etc., hasta que se promulga en España la primera Ley de Educación, la ley Moyano en 1857, y la profesión se hace incompatible con cualquier otro cargo público.

Las primeras clases que tomé bajo mi responsabilidad las llevaban, a su manera los listeros y almacenistas de los que algunos tenían setenta años. Daban clase cuando querían y cuando podían, sin tener la más somera idea pedagógica [...]. Yo fui para organizar e inspeccionar aquellas escuelas, no para impartir personalmente la clase, pero me sentía impotente ante aquel panorama [...]. Pensé que si en lugar de aquellos hombres, con sus respectivas obligaciones, pusiéramos chicas que sólo se ocuparan de la escuela, sería la mejor manera de hacer con ellas lo que convenía [...]. Las chicas podían ser escogidas entre las alumnas a quienes se les viese más aptitudes y estuviesen adelantadas... Yo, podía, además, dedicar algunas horas a dar clases especiales a las auxiliares. Enseguida empecé a seleccionar chicas que iban ocupando el puesto de los hombres en las clases y que rápidamente empezaron a dar resultados óptimos como yo había presumido [...], formaban una verdadera piña de amigas. Se identificaban de tal manera conmigo. Fui creando nuevas escuelas y con ellas estrenando locales y material. (ORTÉS, 1998, p. 37-39).

\section{Identidad de género: las maestras} regeneradoras de modelos culturales para los campesinos

Dolores Medio, formada en los ideales de la II República, asume su papel de madre de la aldea, identidad que la llevará a optar por realizar tareas que exceden los límites de su condición profesional y muy útiles, al abaratar costes en las aldeas. Las autoridades delegan en ella funciones que nada tienen que ver con lo que se exige a una profesional de la educación.

Los trabajos extra que le encomiendan las autoridades locales son asumidos por ella como obligaciones propias de su condición femenina. Condición femenina e imagen profesional están en contradicción en las representaciones de los aldeanos y autoridades locales: por ser mujer tendrá que limpiar, pintar la escuela y organizar una biblioteca en el aula. Y todo pagado de su 
bolsillo, ante la negativa del alcalde a emplear ni un solo duro para tal fin - y a facilitar la lista de las y los niños que hay en el pueblo y deben ser escolarizados.

Julia Ortés describe multitud de tareas extraescolares que serán asumidas por ella sin ninguna resistencia y con el orgullo (término que aparece en sus vivencias muy a menudo) que le produce que las autoridades deleguen funciones que implican poder y responsabilidad. Las noches las dedicaba a primeras comuniones y a ensayar versos para el recibimiento de la Virgen (se refiere a la Virgen de Fátima, que parece iba visitando los pueblos; una llegada muy esperada por la maestra y las autoridades); también pone inyecciones, ayuda al sacerdote, etc. Un sin fin de recuerdos donde la vida privada de la maestra termina por desaparecer en ese entorno de obligaciones asumidas como deberes propios de su condición femenina e imagen profesional.

Cuando me conoció el médico [...], comenzó a encomendarme tareas propias de un practicante [...]. Ponía inyecciones a los niños, a los hombres y a las mujeres (ORTÉS, 1998, p. 42).

\section{Identidades culturales en la España del nacional-catolicismo}

Dolores Medio describe sus primeras experiencias con el recuerdo de una mirada profesional tan atónita como la de sus alumnos, a la espera de que las horas interminables de la clase acaben y pueda escapar de esas paredes sucias, llenas de mapas lúgubres; paredes en las que se respira un modelo cultural que la incomoda. Se queda bloqueada, es objeto de crítica por parte de las autoridades.

Las críticas de los campesinos son constantes, la acusan de comunista, de atreverse a quitar de las paredes los carteles de Historia, de convertir la escuela en un teatro. El pueblo estaba acostumbrado a la otra maestra y ella, que no tiene voto, se ha negado a ayudarlos en las elecciones.
Será una más de las depuradas por ser adepta a los ideales republicanos. Cuando vuelve a la escuela en los años 40, sufre el rechazo de unos campesinos que la ven como una comunista contraria al Régimen. Ya antes de la guerra

[...] los dos bandos la han excluido en la 'lista negra', y acumulan cargos: los chicos juegan en la escuela en vez de estudiar. Los más pequeños la tratan de tú y se duermen en sus brazos... Los chicos y la maestra se bañan en el río, o en cualquier playa próxima con menos ropa de la conveniente [...] hacen títeres en la escuela [...] lo grave es que ellos mismos, los que critican, acuden a su teatro, pagan su entrada y se divierten en las comedias. (MEDIO, 1993, p. 165).

Relata un panorama de miseria, pobreza y muerte. Las generaciones de reemplazo de vencedores y vencidos sentadas en los bancos de la escuela, y ella, la maestra, frente a los dos bandos con una responsabilidad de socialización dura y difícil.

La escuela denuncia el paso de la guerra. Su aspecto no puede ser más desolador: los cristales rotos, sucias las paredes, el techo ahumado, goteras, el suelo cubierto de excrementos de animales [...] Prisión, cuartel, cocina, cuadra... eso ha sido la escuela [...] No es fácil la labor [...] en los bancos de la escuela han de sentarse juntos los hijos de los caídos en los dos frentes [...], los hijos de los fusilados en los dos bandos. (MEDIO, 1993, p. 216).

Resulta curioso que en las vivencias de Julia Ortés no se lean alusiones a las secuelas de la guerra, a los castigos a las y los maestros, etc. La autora se limita a narrar lo vivido: destinos, sueldos y experiencias. Evidentemente esta falta de sensibilidad al cambio que atraviesa España está fuertemente unida a sus representaciones sociales como maestra partidaria de un régimen por el cual parece que el tiempo no pasa, no deja huella, no ha asimilado los cambios sociales. 


\section{Resultados prácticos}

Entiendo que este artículo aporta resultados de utilidad. El momento en que una generación se forma y comienza a ejercer la profesión determina la metodología que emplea siguiendo modelos ideológicos vinculados al antes y el después de la Guerra Civil - cuestión de máxima actualidad en los momentos de reformas educativas que se están produciendo en España con la implantación de la LOMCE$^{4}$ y la vuelta a las metodologías memorísticas -. También la forma en que asumen los cambios sociales que han tenido lugar en España con el proceso de asentamiento de la democracia parlamentaria.

A pesar de las diferencia por la edad, el género es determinante, produciendo un encuentro entre las dos generaciones, que asumen, por caminos distintos, la función de moldear los rasgos culturales de los campesinos en las aldeas rurales. Esta función asignada a las maestras por la dictadura franquista las lleva a identificarse como madres sociales de la aldea. Las dos llegan a entender la maternidad como una función social, que no biológica. Por ello, su condición femenina, en concordancia con las exigencias del régimen, prioriza sobrelas demandas profesionales y laborales profesional. Se trata de elementos impuestos por el régimen franquista, asumidos por ellas que las dejan sin aspiraciones. Esta construcción de género determina la vocación ante la pobreza y la miseria de la España de la postguerra.

Por ello, los dos sesgos generacionales defienden cualidades femeninas para ejercer como maestra. El control ha dado sus frutos y las maestras han hecho suyo los mandatos que llegan de fuera, asumiendo que las demandas de sumisión, paciencia, entrega, sacrificio y vocación son imprescindibles para hacer bien su trabajo como profesionales de la educación. En el caso de Julia Ortés se acentúa esta identidad

4 - La aprobación de la LOMCE, Ley Orgánica para la Mejora de la Calidad Educativa (Ley Orgánica 8/2013, de 9 de diciembre), para la mejora de la calidad educativa está produciendo importantes huellas. Un nuevo currículo ha dejado fuera de los temarios las asignaturas artísticas y las humanidades. Se trata de un importante retroceso que vuelve a incidir en las metodologías memorísticas como medio de aprendizaje. con una imagen del hombre como no apto, incapaz de naturaleza para ponerse al frente de la escuela. Por ello, la maternidad es una clave para comprender en qué medida asumen funciones que exceden a su deber profesional.

Aunque no he tratado en este artículo memorias de maestros, sí quisiera decir que no he apreciado en ellos representaciones sociales que me lleven a utilizar la expresión padre del pueblo. Esa representación está asociada con la figura del cura, relacionada pues con la iglesia y no con la educación (CELA, 1999). En este sentido, resulta curioso en qué medida la imagen de estas maestras se asocia a la exaltación de las cualidades maternales como madres suplentes $y$ concienciadas (STEEDMAN, 1986).

Entre sus identidades se aprecia la imagen del hombre con presencia en el ámbito público y sujeto con demandas salariales, mientras la forma en que ellas viven su profesión evoca espacios ausentes de competitividad laboral y cargados de exigencias vocacionales. Detrás de estas obligaciones que caen sobre ellas, aparece el sentido y la exaltación de una vocación que prima sobre cualquier tipo de aspiración económica. La competitividad laboral y un salario digno de un cabeza de familia estaban reservados al hombre, pues en el caso de la maestra el salario era un sueldo de relleno.

De la lectura de las memorias se desprende que han asimilado su papel, consciente o inconsciente, como reproductoras del régimen. Así como un rasgo muy vinculado a la mujer, que muestran una enorme generosidad al dedicar su tiempo libre en tareas extraescolares sin pedir salario a cambio. En tanto que mujeres las exigencias de moralidad son fuertes y se percibe la imagen inmaculada de la maestra, como virgen del pueblo, de pureza, modelo, imagen, espejo, conducta intachable y transmisora de los roles de género. Poco espacio social quedaba para unas profesionales que debían actuar de forma correcta sin un desvío de la norma que pusiera sobre aviso a las autoridades locales. De lo contrario, su puesto de trabajo peligraba. 
No obstante, la forma en que afrontan los retos y viven el cambio social sí refleja la diferencia generacional. Los métodos lúdicos $\mathrm{y}$ las innovaciones pedagógicas se corresponden con los modelos ideológicos de la II República, las metodologías memorísticas presentan fuertes identidades con los modelos ideológicos del nacional-catolicismo. De la misma manera, los modelos culturales con los que se forman los dos espacios generacionales presentan formas distintas de afrontar los modos de vida en las aldeas y asumir nuevos retos. Por ello, las identidades culturales van variando en los relatos de estas dos maestras en estrecha relación con los modelos ideológicos aprendidos en los inicios de su profesión.
Desde mi punto de vista, la maestra es una pieza clave para comprender la evolución de los modelos culturales. Por ello, este artículo anima a continuar investigando en un colectivo que ha sufrido un olvido imperdonable por parte de las y los investigadores sociales. En el caso de las memorias analizadas, entiendo que lo que quieren recordar o silenciar permite captar el modo en que han asumido o rechazado los modelos ideológicos del nacional-catolicismo. El sentido que dan a lo vivido va creando significantes que nos permiten comprender el modo en que han socializado a las siguientes generaciones, es decir la mía entre otras.

\section{Referencias}

AGULLÓ, Carmen. Mestres valencianes republicanes. Valencia: Universitat de València, 2008.

ALDECOA, Josefina. Historia de una maestra. Madrid: Anagrama, 1990.

ALONSO, Luis Enrique. La mirada cualitativa en sociología. Madrid: Fundamentos, 1984.

BAQUEDANO, Lucía. Cinco panes de cebada. Madrid: Ediciones S. M., 1998.

BORROY, Víctor; VIÑAO FRAGO, Antonio. María Sánchez Arbós: "Mi diario". Zaragoza: Gobierno de Aragón y Caja Inmaculada, 2006. p. 28-62.

CELA, José. Con letra pequeña: reflexiones de un maestro. Madrid: Celeste, 1999.

DEL POZO ANDRÉS, María del Mar. Justa Freire o la pasión de educar: biografía de una maestra atrapada en la historia de España (1896-1965). Barcelona: Octaedro, 2013.

ELIAS, Norbert. El proceso de la civilización: investigaciones sociogenéticas y psicogénicas. México: Fondo de Cultura Económica, 1979.

FLECHA GARCíA, Consuelo. Maestras que dejan huella. Cuadernos de Pedagogía, Madrid, n. 337, p. 10-15, 2004.

GALVÁN LAFARGA, Luz Elena; LÒPEZ PÉREZ, Oresta (Coord.). Entre imaginarios y utopías: historias de maestras. México, D.F.: Programa Universitario de estudios de Género UNAM: Centro de Investigaciones y Estudios Superiores en Antropología Social: Colegio de San Luis, 2008.

JULIÁ DÍAZ, Santos. Camarada Javier Pradera. Madrid: Círculo de Lectores, 2013.

KUHN, Manford H. Major Trends in Simbolic Interactionism. The Sociological Quartely, v. 5, n. 1, p. 61-84, jan. 1964.

MANNHEIM, Karl. The problem of generation. In: KEESKEMETI, Paul (Ed.). Essays on the sociologu of knowledge. London: Routledge \& Kegan Paul, 1952. p. 276-322.

MEAD, George Herbert. The social self. The Journal of Philosophy, v. 10, p. 364-380, 1913.

MEDIO, Dolores. Diario de una maestra. Madrid: Castalia, 1993. 
MOLERO PINTADO, Antonio. Los maestros republicanos: legislación y conflictividad profesional (1931-1936). Historia de la Educación: Revista Interuniversitaria, Salamanca, n. 16, p. 285-302, 1997.

ORTEGA Y GASSET, José. En torno a Galileo: obras completas. Revista Occidente, v. 5, p. xx, 1951.

ORTÉS, Julia. Vivencias de una maestra. Madrid: Narcea, 1998.

ORTÍ, Alfonso. La apertura y el enfoque cualitativo o estructural: la entrevista abierta o semidirectiva y la discusión en grupo. In: GARCÍA FERRANDO, Manuel; IBÁÑEZ, Jesús; ALVILA, Francisco (Eds.). El análisis de la realidad social: métodos y técnicas de investigación. Madrid: Alianza, 1986. p. 120-156.

ORTÍ, Alfonso. Estratificación social y estructura del poder: viejas y nuevas clases medias en la reconstrucción de la hegemonía burguesa. In: W.AA. Política y sociedad: estudios en homenaje a Francisco Murillo Ferrol. Madrid: Centro de Investigaciones Sociológicos, 1987. p. 711-736.

PINA, Antonio. La generación del 56. Madrid, Marcial Pons, 2010.

SAN ROMÁN, Sonsoles (Org.). Evolución de las actitudes culturales y las representaciones sociales en las y los maestros del nivel de primaria (1970-2008). Madrid: Ministerio de Igualdad: Instituto de la Mujer, 2009.

SAN ROMÁN, Sonsoles (Ed.). La maestra en el proceso de cambio social de transición democrática: espacios históricogeneracionales. Madrid: Instituto de la Mujer, 2001.

SAN ROMÁN, Sonsoles. Una maestra republicana: Julia Vigre, protagonista del cambio social en la España del siglo XX. Madrid: Machado, 2015.

STEEDMAN, Carolyn. La madre concienciada: el desarrollo histórico de una pedagogía para la escuela primaria. Revista de Educación, Madrid, n. 281, p. 193-211, 1986.

TIERNO GALVÁN, Enrique. El espacio histórico generacional de Costa. In: COSTA, Joaquín. Costa y el neorregeneracionismo. Barcelona. Barna, 1961. p. 17-18.

VARELA, J. Mujeres con voz propia. Madrid: Morata, 2011.

VIÑAO FRAGO, Antonio. Autobiografías, memorias y diarios como fuente histórico-educativa: tipología y usos. In: RUÍZ BERRIO, Julio (Ed.). La cultura escolar de Europa: tendencias históricas emergentes. Madrid: Biblioteca Nueva, 2000. p. 169-209.

VIÑAO FRAGO, Antonio. Autobiografías, memorias y diarios de maestros y maestras en la España contemporánea (siglos XIX-XXI). Cultura Escrita \& Sociedad, n. 8, p. 183-200, abr. 2009.

VIÑAO FRAGO, Antonio. Memoria escolar y guerra civil. Autobiografías, memorias y diarios de maestros y maestras. Cultura Escrita \& Sociedad, n. 4, p. 171-202, jun. 2007.

VIÑAO FRAGO, Antonio. Relatos y relaciones autobiográficas de profesores y maestros. In: ESCOLANO BENITO, Agustín; HERNÁNDEZ DÍAZ, José María. La memoria y el deseo: la memoria y el deseo. Cultura de la escuela y educación deseada. Valencia: Tirant lo Bllanch, 2002. p. 135-171.

W.AA. Las maestras de la República. Madrid: Los Libros de la Catarata, 2012.

WEBER, Max. La concepción luterana de la profesión: tema de nuestra investigación. In: WEBER, Max. La ética protestante y el espíritu del capitalismo. Barcelona: Península, 1985. p. 62-87.

Recebido en: 18.02.2014

Aprobado en:13.08.2014

Sonsoles San Román Gago es catedrática de la Escuela Universitaria del Departamento de Sociología de la Facultad de Ciencias Económicas y Empresariales de la Universidad Autónoma de Madrid, España. 